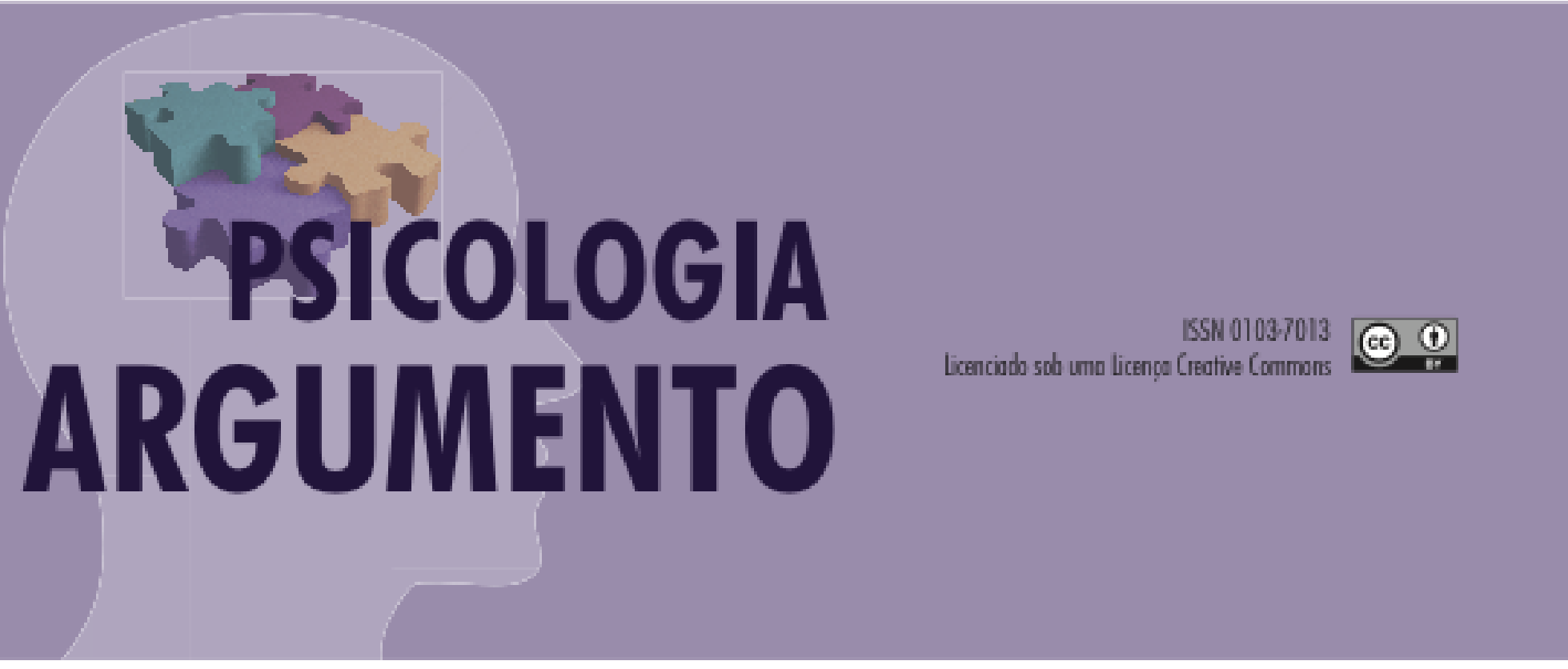

doi 10.7213/psicol.argum.33.082.A006

\title{
Subjetividade pós-moderna e relações sociais: implicações para a efetividade do sistema de justiça
}

\author{
Postmodern subjectivity and social relations: implications for the \\ effectiveness of the legal system
}

Maria Cristina Neiva de Carvalho [a], Claudia Maria Barbosa ${ }^{[b]}$

[a] Professora de graduação de Direito e de Psicologia da Pontifícia Universidade Católica do Paraná. Coordenadora da Pós-graduação lato sensu em Psicologia Jurídica da Pontifícia Universidade católica do Paraná. Curitiba-

Paraná - Brasil. Endereço eletrônico: cristina.n@pucpr.br

[b] Professora titular de Direito Constitucional da Pontifícia Universidade Católica do Paraná - PUCPR. Professora do Programa de Mestrado e Doutorado em Direito da PUCPR. Curitiba- Paraná - Brasil. Endereço eletrônico: claudia.mr.barbosa@gmail.com

\section{Resumo}

O desafio da efetividade do sistema de justiça atual é de alta complexidade, pois apesar de ser competência do âmbito jurídico, vários campos de conhecimento estão implicados, sendo necessária escolha de paradigma adequado para análise. Aborda-se o tema mediante revisão de literatura sob a ótica do paradigma da complexidade, onde Ciências Sociais, Psicologia e Direito se entrelaçam, considerando a pós-modernidade como contexto que circunscreve o funcionamento do sistema de justiça. O objetivo é demonstrar a influência da subjetividade contemporânea no funcionamento do sistema de justiça. Para isso, apresenta-se o mundo contemporâneo regido por novos ditames, o que propicia que a subjetividade e conduta dos indivíduos, respondam a uma lógica maior que determina sua forma de ser-no-mundo sendo 
que organizações sociais - incluindo o sistema jurídico - também podem ser analisadas sob a ótica dessa ordem social específica. Na contemporaneidade os indivíduos buscam bem-estar a qualquer preço, seja pelo consumo excessivo, uso de drogas, manipulação de regras, ou seja acionando o sistema de justiça na procura da sua justiça. Na medida em que indivíduos se libertam das amarras sociais na busca de viver de acordo com seu Eu , mais suas relações complicam, criando inúmeras demandas judiciais pelo comportamento consumista e desdobramentos das desigualdades e violação de direitos. Conclui-se que os desafios da efetividade do sistema de justiça talvez impliquem em descompassos entre o que seria efetividade para esse sistema e para a demanda dos sujeitos pós-modernos que o procuram, a qual é resultante de funcionamento social específico.

Palavras-chave: subjetividade; pós-modernidade; efetividade; sistema de justiça.

\begin{abstract}
The challenge of the effectiveness of the current legal system is highly complex, because, despite being the competence of the legal sphere, various knowledge fields are involved, requiring choice of suitable paradigm for analysis. The issue is addressed by means of literature reviewing under the perspective of complexity paradigm, in which Social Sciences, Psychology and Law are intertwined, considering postmodernity as context that limits the legal system operation. The goal is to show the influence of contemporary subjectivity on the legal system operation. For this purpose, the contemporary world is presented governed by new dictates, which provides that subjectivity and individual's behavior respond to higher logic that determines its way of being in the world; and social organizations - including the legal system - can also be analyzed under the perspective of this particular social order. In contemporary times, individuals seek well-being at any cost, either by excessive consumption, drug use, or maneuvering the rules, i.e., triggering the legal system, searching their righteousness. To the extent that individuals break free from social constraints in the pursuit of to live according to themselves, their relations become more complicated, creating numerous lawsuits by consumerist behavior and consequences of inequalities and violation of rights. It is concluded that the challenges of the effectiveness of the legal system may involve mismatches, regarding what would be effective for this system and the demand from postmodern individuals who seek it, which are the result of specific social operation.
\end{abstract}

Keywords: subjectivity; postmodernity; effectiveness; legal system.

\title{
Introdução
}

O desafio do sistema de justiça operar efetivamente na atualidade tem demonstrado que é problemática de alta complexidade pois, apesar da competência ser do âmbito jurídico, denota-se que aspectos de vários campos de conhecimento estão implicados. Somente esse motivo, já seria suficiente para se compreender que a situação exige a escolha de paradigma adequado para sua respectiva análise. Sendo assim, esse artigo objetiva inicialmente, apresentar o paradigma do pensamento complexo defendido por Edgar Morin como uma possibilidade produtiva de abordagem da questão da efetividade dos serviços jurisdicionais. Foi realizada a escolha desse olhar sobre o fenômeno-foco do presente estudo, por entender ser a mais adequada para uma discussão onde as Ciências Sociais, a Psicologia e o Direito se entrelaçam na formação do problema da efetividade do sistema de justiça e possivelmente nas alternativas de enfrentamento que podem surgir. A opção por essa abordagem fez-se pela sua abertura para a comunicação entre os saberes, propiciando um diálogo dinâmico onde a relação entre os partícipes é constante e contínua.

Considerando que a pós-modernidade é o contexto que circunscreve o fenômeno da efetividade do sistema de justiça, faz-se necessário aqui apresentar a proposta de entendimento do mundo contemporâneo resultante da passagem de uma sociedade moderna, com todas as especificidades desta, para uma sociedade regida por novos ditames. A meta é demonstrar o quanto a conduta dos indivíduos, regida por sua subjetividade responde a uma 
lógica mais ampla que determina sua forma de ser-no-mundo. Propõe-se que os diversos grupos formais e informais, assim como os sistemas institucionais - o que vale para os órgãos responsáveis pela justiça - também podem ser analisados sob essa ótica, pois não são marginais a uma ordem social específica. Portanto, o objetivo do presente artigo é demonstrar a influência da subjetividade contemporânea no funcionamento do sistema de justiça e para essa finalidade discorre-se sobre subsídios teóricos que contemplam o tema.

\section{Paradigma da complexidade e a comunicação entre as disciplinas}

A sociedade contemporânea confronta-se com uma série de problemas que urgem abordagens diferenciadas de vários campos de conhecimento para que se minimize o impacto das consequências dessas dificuldades. Aqui poder-se-ia elencar diversos assuntos atuais que têm sido foco de pesquisa e intervenção das ciências puras e aplicadas: a questão ambiental, a globalização da economia, o papel e impacto da tecnologia na pósmodernidade, a efetiva implementação dos direitos humanos, dentre tantas outras temáticas.

Faz-se importante salientar, que em todos esses grandes temas existe uma articulação, seja direta ou indireta, com o Direito enquanto campo de conhecimento e de aplicação. Isto é, o Direito está sendo convocado cada vez mais a se manifestar com suas contribuições para a promoção da sociedade contemporânea.

No entanto, os pressupostos positivistas de vários campos de conhecimento, dentre eles o Direito, são de alguma forma desestabilizados por deflagrar-se um momento da sociedade, denominado pós-moderno, quando as bases epistemológicas até então utilizadas parecem não mais se aplicar à configuração que por ora se encontra na sociedade. O surgimento do paradigma da complexidade que tem em Edgar Morin (1996b) um de seus principais estudiosos, intenta fornecer subsídios para uma nova abordagem das problemáticas atuais, que parecem em muito diferir das referentes ao mundo da idade média e moderna.

A constatação de que atualmente as coisas são articuladas e se interdependem, traduz-se no termo tão amplamente hoje utilizado - a globalização. A passagem de uma abordagem científica que dicotomiza a realidade para uma abordagem que integra fatos, é muito bem apresentada por Morin (1996b) em seu texto "Epistemologia da Complexidade". A sociedade humana passa então a ser entendida como um grande sistema composto de vários subsistemas dinâmicos e que mantêm algum tipo de relação entre si.

Na mesma direção de pensamento, Casanova (2006) traz a inevitável abordagem interdisciplinar diante da complexidade do mundo pós-moderno para que se tenha uma visão mais completa da realidade natural e social. Segundo o autor, esse novo conhecimento produzido a partir da integração entre as ciências, não abandona os parâmetros filosóficos e científicos anteriores, mas propicia a criatividade no sentido de estabelecer novas conexões cognitivas propiciadoras de mudanças para os grandes dilemas do capitalismo e que não levem esse sistema a processos autofágicos.

Santos (2005) também confirma a sua percepção de que a ciência moderna se encontra em crise o que conduz à necessidade de se utilizar um novo paradigma por ele denominado ciência pós-moderna, enfatizando a importância de que se reflita constantemente sobre a ciência que se faz. Em especial, focalizam-se suas observações sobre o fato de que a ciência moderna fundamentada em pressupostos positivistas exclui da produção de conhecimento, todo elemento não cognitivo - ou seja, as emoções, desejos, paixões, dentre outros fenômenos psíquicos - por acreditar que estes alteram a 
racionalidade essencial da ciência. $\mathrm{O}$ autor defende uma proposta científica que aproxime mais e com maior tolerância, os processos cognitivos e não cognitivos, dando como exemplo a total incompatibilidade das teorias feministas com o modo da ciência racional da era moderna, sendo não por acaso, que as questões do feminismo são identificadas com o paradigma pós-moderno. $\mathrm{O}$ autor retoma a discussão da necessidade de uma nova forma de se abordar a realidade quando identifica que muitas vezes os grandes problemas das ciências sociais coincidem como sendo também problemas para as ciências naturais. Do que se deduz que provavelmente a forma dicotomizada de se estudar a realidade esteja sendo improdutiva.

Acredita-se, portanto que a mudança de paradigma das ciências se faz essencial uma vez que o paradigma vigente parece não contemplar mais as necessidades da sociedade contemporânea. O pensamento simplificador vigente ainda no século XXI desconsidera a complexidade do real, ao contrário do pensamento complexo que inclui o máximo possível as formas simplificadoras de se pensar, mas rechaçando seus efeitos nefastos para a compreensão e intervenção sobre a realidade: a mutilação dos fatos, reducionismo, visão unidimensional e ofuscante da realidade, acreditando-se que o real é o que se determina a partir dessa perspectiva. Além disso, a proposta do pensamento complexo alimenta-se do que Morin (2007, p.7) denomina de uma "tensão permanente" entre a intenção de se buscar um saber não fragmentado e não reducionista e o fato de ter que se reconhecer que qualquer conhecimento é em si incompleto e inacabado.

Numa análise mais funcional da manutenção desse paradigma nos últimos séculos, Morin (2000) lembra que não se pode esquecer que a própria produção de conhecimento e a forma pela qual isso se dá é influenciada por inúmeras forças anônimas, principalmente pelo próprio Estado. A visão mutilada da realidade pode ser útil para diferentes interesses, onde se mantém um monopólio de saberes circunscritos a uma realidade aparentemente simplificada.

Mais especificamente quando se considera a realidade antropossocial de uma perspectiva linear e restrita, que não inclui a micro dimensão (indivíduos) e a macro dimensão (conjuntos das sociedades) certamente serão geradas ações que também são mutiladoras sobre essa realidade. Essa situação é denominada por Morin de "patologia da razão" e definida como "a racionalização que encerra o real num sistema de ideias coerente, mas parcial e unilateral, e que não sabe que uma parte do real é irracionalizável, nem que a racionalidade tem por missão dialogar com o irracionalizável” (Morin , 2007, p.15).

Uma vez constatado que na realidade da complexidade, existem vários níveis, e que o ser humano é hiper-complexo, exige-se que o conhecimento produzido por ele e para ele considere a intersecção de diferentes campos de conhecimento. Tal fato é citado por Morin (2007) ao caracterizar a postura sistêmica que se situa num plano transdisciplinar, implicando ao mesmo tempo considerar a unidade e a diferenciação das ciências no seu objeto de estudo e intervenção. Nas palavras do autor "a unidade da ciência respeita a física, a biologia, a antropologia, mas quebra o fisicismo, o biologismo, o antropologismo" (Morin, 2007, p.50). Denota-se que a abordagem fundamentada no positivismo lógico tem o sentido para o autor de uma epistemologia policialesca, não se permitindo olhar para onde deve realmente se olhar hoje - ou seja - para o incerto, ambíguo, contraditório (Morin, 2007).

Dufour (2008) também alerta para o risco do conhecimento contemporâneo dicotômico principalmente nas ciências do homem, onde cada campo de conhecimento dá o 
seu veredicto sobre o fenômeno em questão, de maneira tão especializada que não rara vezes se omite o todo, isto é, de quem se fala.

Se a forma de se fazer ciência atualmente não está mais atingindo seus objetivos, deve-se rever os pressupostos utilizados para se estudar as diferentes realidades, já que não é possível mudar a realidade. Essa mudança de paradigma afetará todo o sistema de pensamento - a ontologia, epistemologia, lógica, a prática, a sociedade e a política (Morin, 2007). Portanto implica em sair de um lugar, de certo conforto, onde se busca explicar algo complexo a partir de premissas simplificadas, que são aceitas pelos interlocutores e onde se percorre um raciocínio sutil que implica engrenagens e sistemas conhecidos. Mostra-se extremamente difícil sair dessa área de conforto e modificar o conceito angular que mantém toda a construção intelectual simplificadora que não inclui a constante relação entre harmonia $\mathrm{x}$ desarmonia de fatos e saberes.

Em especial nas ciências humanas e sociais, Morin (2007) aponta a tendência de não se considerar a complexidade dos fatos, como se fosse possível, por exemplo, estudar pedagogia sem considerar aspectos psicológicos das relações pedagógicas. Passa-se a acreditar que as categorias criadas no mundo acadêmico sejam realidades o que tem como consequência, estudos e ações aleijadas e por isso, não eficazes. Seriam disfuncionais por seguirem o paradigma científico tradicional que se fundamenta em três princípios: da simplicidade, da estabilidade e da objetividade, o que já anuncia a visão restrita de um fato, que pressupõe-se não modificar e ser possível analisá-lo sem nenhuma interferência do observador. Já o paradigma contemporâneo implica em três pressupostos: a complexidade, a instabilidade e a intersubjetividade. Entende-se por ele, que a realidade é formada por múltiplas partes interconectadas entre si e que por isso estabelecem relações contínuas e dinâmicas o que torna os sistemas instáveis, sendo o observador mais um fator presente na rede relacional e que deve também ser considerado no estudo e proposições (Vasconcellos, 2003).

Em sua recente obra "A via para o futuro da humanidade" Morin (2013) analisa as consequências para a humanidade, da globalização, do desenvolvimento desenfreado, do pensar e agir de maneira reducionista . Aborda o impacto dessa configuração para o conhecimento alertando que o mundo ocidental apresenta dois tipos do que ele denomina de "carência cognitiva": colocar os saberes em compartimentos acaba fragmentando os problemas fundamentais e, a primazia da racionalidade traz a ilusão do domínio do conhecimento.

Passando pela análise de questões políticas e sociais da humanidade, das reformas do pensamento na educação, saúde, trabalho, urbanismo, questões éticas, fases de desenvolvimento humano, dentre muitos outros aspectos, Morin (2013) sugere a progressão de vias reformadoras em todas essas áreas para se regenerar o mundo dos homens. Em síntese suas propostas passam pela postura de integração e religação de saberes, da própria articulação entre as várias reformas necessárias. Mas como ele mesmo afirma de maneira enfática "as reformas são solidárias, mas não são apenas institucionais, econômicas, sociais; são também mentais e necessitam de uma disposição para se conceber e se comprometer com os problemas globais e fundamentais, atitude que requer reforma da mente" (Morin, 2013,p. 382).

Essa nova forma de pensar o conhecimento já foi exposta por Morin (1996b), quando apontava a transdisciplinaridade como uma via necessária para o enfrentamento da dicotomia do conhecimento. $\mathrm{O}$ autor deixa claro que a proposta de interdisciplinaridade não 
dá conta dessa problemática, pois demonstra que nas chamadas práticas interdisciplinares, inicialmente cada disciplina intenta que se reconheça sua soberania territorial e, depois disso mediante ínfimas trocas, se confirmam as fronteiras entre os saberes ao invés de se relativizarem essas divisões para a construção de novos saberes (Morin, 1996b). Seu convite no final do século XX seria uma nova transdisciplinaridade que vá além de definir fundamentos comuns, e promova verdadeira comunicação entre os saberes. Os esquemas cognitivos necessários para o pensar transdisciplinar expõe que a comunicação necessária entre as disciplinas faz que cada uma delas se questione, relativize suas verdades. Não se trata obviamente de destruir o conhecimento já construído, mas sim de ecologizar as disciplinas, considerando tudo que lhes é contextual e que, de uma forma ou de outra está interligado.

Com a mesma intenção, na obra organizada por Santos e Menezes (2009), "Epistemologias do Sul", depreende-se em vários capítulos o entendimento de uma epistemologia globalizada onde a integração de saberes pode ser uma das ferramentas para a sustentabilidade global baseada na efetivação de direitos humanos. Essa premissa poderia ser transportada para várias áreas do Direito onde se identificam grandes dificuldades em se prestar serviço jurisdicional efetivo, justamente por se referirem a demandas ao sistema de justiça onde a questão jurídica é uma ponta de iceberg, o que exige que se recorra a campos de conhecimento alternativos ao Direito para que a lei seja efetiva, tanto individualmente como para o alcance social da mesma.

$\mathrm{Na}$ realidade brasileira conta-se como exemplo prático dessa situação, a recente discussão sobre a redução da idade penal, que tem suscitado reflexões em diversas áreas de conhecimento tais como ciências jurídicas, Sociologia, Psicologia, Pedagogia, Filosofia, dentre outras. Pois, embora a infração cometida por adolescentes seja objeto de intervenção do Direito, evidencia-se que é resultante de uma trama complexa de variáveis que não podem ser desconsideradas na abordagem do problema, sob o sério risco de incremento de atos violentos cometidos por adolescentes por se ignorar a violência cometida contra adolescentes, seja ela direta ou indireta pela não efetivação das garantias de direitos das crianças e adolescentes em nossa sociedade.

A proposta ganha ressonância em Sen e Kliksberg (2010) quando os autores afirmam que o desafio para a ética do desenvolvimento exige que se integre a riqueza de conhecimentos advindos de todas as partes do planeta, conhecendo profundamente as necessidades específicas de cada parcela da humanidade, e implementando políticas de solidariedade e responsabilidade social. Ao demonstrarem uma serie de dados de órgãos oficiais e resultados de pesquisas acadêmicas, fundamentam o quanto a economia de mercado não está atendendo o que seria uma premissa para a democracia - o provimento de direitos fundamentais. Para isso, defendem ser de muita importância que a ética e a economia se aproximem, campos estes que tradicionalmente são compreendidos como em oposições, mas cuja integração mediante o uso de estratégias de pesquisa e intervenção que pressuponham a articulação de saberes, pode trazer resultados benéficos para a sociedade.

Portanto, a premissa aqui exposta é que os fenômenos que são objetos das ciências na contemporaneidade exigem constante autocrítica dos estudiosos sobre os limites e possibilidades do instrumental metodológico de seu campo do saber. Pois, pelo que indicam os autores acima citados, urge a necessidade de se mudar as lentes de análise da realidade e, por conseguinte se expor aos riscos de compartilhar com outros campos o seu saber, relativizando verdades e compondo novas formas de conhecimento. 


\section{Subjetividade pós-moderna: a nova forma de ser no mundo}

A conjuntura sociológica em um tempo e lugar específicos tem importante influência na construção da subjetividade dos sujeitos e consequentemente na qualificação das relações que estabelecem entre si e com as instituições formais ou informais. Sendo assim recorre-se a alguns autores que, seja da perspectiva das ciências sociais, filosofia ou da psicologia fundamentada nos fenômenos sociais, traçam algumas características do mundo contemporâneo e a forma como estas se relacionam com o funcionamento dos sujeitos na pós-modernidade.

Zygmunt Bauman é um autor com vasta produção sobre essa temática . No estudo de várias de suas obras é possível depreender que a efemeridade, a superficialidade e a fluidez são aspectos que permeiam as relações sociais atuais, onde se constatam vinculações frágeis com pessoas e objetos que fácil e rapidamente são descartados. A meta dos sujeitos contemporâneos é uma vida hedonista e, fundamentados nessa premissa, quando os indivíduos se deparam com barreiras para a consecução de tal objetivo, os obstáculos são enfrentados muitas vezes pela negação e exclusão dos mesmos ou ainda com a simples troca de objeto e pessoas com as quais o sujeito está se relacionando e com quem encontrou algum desprazer. Tais pressupostos podem ser identificados em toda a extensão de obras como "O Mal-Estar da Pós Modernidade" (Bauman, 1998), "Modernidade Líquida" (Bauman, 2001) e essa configuração psicossocial é entendida algumas vezes como expressão de processos onde o valor está no que os indivíduos podem fornecer uns aos outros e não no ser humano em si. É uma perspectiva eminentemente utilitarista das relações humanas e que se estende para as relações sociais e institucionais.

Deflagra-se a partir desse contexto relacional uma crise de valores, onde a questão ética das relações assume diferentes proporções implicando que alguns valores até então tidos como esperados nas relações entre as pessoas, tendam a se tornar cada vez mais raros, tais como a empatia, lealdade, coerência, respeito. Para Bauman (2001) essas categorias relacionais são incompatíveis com o que denomina modernidade líquida que tem como palavras de ordem: esquecer, apagar, desistir e substituir.

Esse processo tem impacto consubstancial no significado tempo-espaço para o homem e, ao denominar a forma de viver atual como "vida instantânea" Bauman (2001, p.143) aponta que as referências do passado, da história do indivíduo ou de toda uma sociedade sempre foram diretrizes importantes para a evolução da humanidade. Da mesma forma, o olhar com esperança para o futuro, na expectativa inclusive de uma grande durabilidade desse futuro, haja vista a ideia cristã de eternidade, representava fonte de energia para o agir humano. A realidade agora é outra. Pois a motivação principal da vida instantânea é buscar a gratificação, procurando se excluir das consequências da mesma, principalmente no que se refere às responsabilidades correlatas. Não é o passado que define como ser no mundo e muito menos o futuro. Bauman (2001) expressa a preocupação nesse sentido pois é uma modalidade totalmente nova do viver e por isso, desconhecida, que gera dificuldades em se compreender a conduta humana e consequentemente abordar uma cultura que se mostra indiferente a anteriormente tão desejada eternidade, assim como evita a durabilidade das coisas e relações. $\mathrm{O}$ autor chama a atenção para a consequência de que também a moralidade do agir humano esteja diferenciada no sentido de sua fuga da responsabilidade dos efeitos imediatos ou não, de seus atos para com o outro. Conforme afirma Bauman (2001,p.149) "o advento da instantaneidade conduz a cultura e a ética humanas a um território não-mapeado e inexplorado, onde a maioria dos hábitos aprendidos para lidar com os afazeres da vida perdeu sua utilidade e sentido". 
Para Bauman, (1999) de alguma forma, a globalização representa perda de identidade, pois agora, a formação e desenvolvimento dos indivíduos podem ser globais o que não necessariamente é negativo. No entanto, deixam de existir referenciais pessoais e o sujeito fica a mercê de códigos, induções e manipulações sociais dos quais na maioria das vezes não tem consciência. Por outro lado, a vida de comunidades inteiras é compartilhada, via espaço cibernético, ao qual muitas vezes os próprios integrantes não têm acesso e paralelamente sua identidade cultural se perde no mundo globalizado. São também questões éticas que se impõem seja com relação aos sujeitos reféns da globalização, seja de grupos sociais que são expostos sem a sua participação.

A emergência desse novo sujeito impõe reflexões acerca da necessidade de uma nova ética que considere as características da contemporaneidade. A existência de uma sociedade onde a tecnologia permite ao homem ter ações com desdobramentos que se estendem no tempo e espaço, conduz a revisão do conceito de ética diferente do tradicional, onde o homem tinha potencialidades mais restritas e o impacto de suas atitudes era considerado preponderantemente em curto prazo.

Clarifica-se que a referência é sobre como estão estruturados os valores na pós modernidade, que conduzem a uma forma de ser e se relacionar com o mundo diversa da modernidade. A escassez de valores, associada ao combate e até mesmo negação dos limites, típicos da subjetividade contemporânea, conduz ao fato de que os sujeitos, em busca da satisfação de suas necessidades, enfrentem as dificuldades inerentes à vida, às relações humanas e institucionais, com uso da força - mesmo que fora da lei - , da simples substituição de objetos e desistências de percursos e metas que se mostram frustrantes. Para Lebrun (2004) em seu ensaio "Um Mundo sem Limite" a função da autoridade paterna simbólica encontra-se em declínio progressivo na pós-modernidade. E, sendo essa função que limita as atitudes dos seres humanos, quando de alguma forma essas atitudes trarão prejuízos para ele mesmo ou para seu semelhante, configura-se um terreno fértil para processos individuais e coletivos onde o outro não é considerado, onde não há impedimentos, onde não há saciedade de necessidades. Esses fatos podem ser identificados não somente nos sujeitos singulares, mas também em categorias comportamentais coletivas que se manifestam com muita intensidade na atualidade, tais como: economia globalizada, crise do Estado enquanto providência, excessivo uso da tecnologia, ênfase ao individualismo, altos níveis e diferentes modalidades de violência, e a busca excessiva aos recursos jurídicos para que se atinja a finalidade individual.

A crise das instituições que representam a normatização e a autoridade, pode ser observada em várias instâncias na pós-modernidade. Nas diferentes configurações familiares atuais denota-se a carência da autoridade parental nas famílias, onde os pais buscam incessantemente a sua própria satisfação através dos filhos e também procuram atender os desejos das crianças de maneira ilimitada. Nas instituições escolares que teriam o papel de ampliar a socialização das crianças, não é raro observar o despreparo e muitas vezes o desespero dos educadores diante de atitudes de alunos que ignoram qualquer regra posta. A constatação estende-se para instituições religiosas que historicamente representaram a pregação de regras e normas para o bem viver de acordo com crenças específicas e hoje são alvos de escândalos de várias ordens manifestando que sua representação social de caminho para a integridade moral e de virtudes do ser humano se encontra abalada. Não é diferente com os representantes das várias instituições estatais que se encontram profundamente afetadas na credibilidade da sociedade, que nelas não têm mais o respeito pela autoridade que poderiam ou deveriam representar. Em especial o Poder Judiciário, depositário da lei, encontra-se em crise deflagrada onde, por exemplo, não é raro um jurisdicionado fora da lei utilizar diante da pena recebida as palavras não dá nada. 
Do ponto de vista da estruturação psíquica e consequente expressão da subjetividade, tem-se como consequência dessa deficitária ou inexistente relação com limites, adultos infantilizados que não se desenvolveram no sentido de sair da posição egocêntrica, onipotente e sem limites (Dufour, 2008). Assim, já se convive na contemporaneidade com número cada vez mais significativo de adultos vorazes, hedonistas e que buscam o bemestar a qualquer preço, seja pelo consumo excessivo, seja pelo uso de drogas, seja pela manipulação de regras, seja acionando o sistema de justiça na busca da sua justiça.

Esse autor compara os sujeitos contemporâneos a um grande rebanho, que impedido de ter acesso ao pensamento crítico ao mesmo tempo que é ávido pelo prazer mediante a expressão de pulsões egoístas, torna-se presa fácil de um outro grande grupo detentor do poder sobre o mercado. Nesse processo perdem-se os limites internos psíquicos e externos, estes referentes muitas vezes a aspectos transcendentais. E o liberalismo avança a passos largos, preparando desde a infância o indivíduo para consumir, pois como afirma Schor (2009) os arquitetos da cultura contemporânea, representados por empresas de publicidade e propaganda e meios de comunicação já voltam seus projetos publicitários e de sedução para consumo, às fases iniciais do desenvolvimento humano. Nos Estados Unidos se gasta muito com anunciantes voltados para o público infantil, que hoje representa variável importante no funcionamento financeiro familiar e, sendo por isso as crianças o ponto central da cultura de consumo norte americana. A preferência das crianças e suas opiniões dirigem as estratégias de mercado, que em contrapartida sempre lhe acenará a possibilidade de satisfazê-las. Por outro lado, os adultos que as acompanham em seu desenvolvimento, nas esperadas funções parentais, não têm a dimensão da consequência disso para o próprio futuro de seus filhos. Por que, então essa criança, um dia se afastaria do mercado, pois afinal é ouvida, valorizada e atendida em seus desejos?

Esse processo se complica quando segundo Dufour (2008), a pós-modernidade sedimentada sobre o poder da técnica vende a ilusão de que tudo pode ser resolvido com a tecnologia. Os avanços nessa área reforçam a fantasia humana de que os problemas de tempo, de espaço e de tantos outros limites que a realidade apresenta, mais cedo ou mais tarde serão sanados pela oferta de serviços, objetos, estruturas que contornem as barreiras impostas. O problema para o autor, é que está havendo esquecimento de que a produção depende da matéria prima, seja qual for, o que só é lembrado pelo mercado quando os recursos não estão disponíveis ou ameaçam acabar. Isto é, a exploração do meio ambiente se dá também sobre bases de uma subjetividade coletiva sem limite para produzir e consumir, mas que convive com o anúncio claro e preventivo sobre a imposição dos limites dos recursos ambientais não somente para o funcionamento do mercado mas até mesmo para as necessidades básicas humanas. A ideia subliminarmente divulgada pelo liberalismo que há alguma força divina que não deixará o produto faltar, certamente tem que ser abandonada segundo Dufour (2008), sob o risco das faltas se imporem e, uma vez mais, ao serem administradas novamente por grupos seletos, tornem a convivência humana uma barbárie. Deixar acontecer, não é a saída, o limite e a escolha de permanecer ou não no rebanho deve ser de cada um.

As noções de tempo e espaço, que por si são limitadoras também ganham novas expressões numa sociedade onde a tecnologia permite se estar em lugares distantes em tempo real. A diretriz é: posso ser quem quero, posso ir onde e quando quero, e farei o que preciso for para atingir meus objetivos. O devir se confunde com o aqui-agora num jogo perigoso que pode trazer consequências nefastas para o indivíduo e para a sociedade. Portanto, o sujeito contemporâneo vive um paradoxo, pois evita as interferências coletivas sobre suas motivações pessoais e ao mesmo tempo nunca se encontrou tão exposto na sociedade pela via das redes sociais. Tem-se, portanto, uma nova configuração psíquica que 
se caracteriza por subjetividade complexa, paradoxal, múltipla e que se reorganiza constantemente em função das rápidas transformações sociais.

No entanto, diante desse contexto volátil e instável das manifestações subjetivas na busca do estado hedonista, obviamente o desprazer de alguma forma se impõe, mediante inevitáveis limitações que se encontram na vida. Portanto aí se instala o conflito, entre querer e poder do sujeito contemporâneo, lembrando que conflito é inevitável em qualquer época da história da humanidade, mas na pós-modernidade instaura-se uma urgência em saná-lo a qualquer preço. Esse desprazer caracteriza-se pela insuportabilidade de se conviver com a impossibilidade, gerando buscas constantes de objetos externos para a satisfação de suas intenções. E aí se consome drogas, comida, roupas, sexo, lazer, informações, serviços públicos e privados, e por que não, a justiça oferecida pelo Estado.

Bauman (2008) descreve a intrínseca relação entre os indivíduos e as mercadorias, onde estas são partícipes da identidade do sujeito contemporâneo, mas que existem porque são criadas demandas por aqueles que dela necessitam para manter o jogo de oferta e procura. O sociólogo estuda profundamente a questão do consumo na sociedade atual e suas relações com o que representam as pessoas nessa configuração, concluindo em primeiro lugar que os sujeitos na lógica do mercado são ao mesmo tempo, promotores de mercadorias e são as próprias mercadorias.

Se o consumo fundamenta-se na busca do prazer e evitação do desprazer e, para haver mercado ativo deve haver consumo além de ser o sujeito uma mercadoria, ele também não pode estabilizar. Esse padrão é repetido, portanto nas relações humanas e institucionais que se tornam objeto de consumo para os indivíduos, ao mesmo tempo em que estes são mercadorias para aqueles. E não basta somente consumir, deve-se desperdiçar, para que surjam novas necessidades e motivações e, assim a conduta humana vai sendo monitorada pelo mercado para que a economia consumista se mantenha.

A questão do consumo na pós-modernidade também é abordada por Lipovetsky (1989), referindo-se ao fato de representar de maneira definitiva o alcance de meta antiga da era moderna e que se traduz no controle total da sociedade e a libertação das esferas privadas, com o diferencial de que isso na atualidade ocorre em função de necessidades que se diversificam e flutuam no mesmo ritmo que mudam princípios, papéis e estatutos. A sociedade caracterizada pela busca do bem-estar cria necessidades e produtos que se traduzem em abandono de tradições, da ética moderna, retirando do indivíduo os seus referenciais de espaço-tempo, de vida quotidiana, de suas relações e de si mesmo. O controle do consumo atual funciona por sedução, onde o indivíduo adquire objetos, ideias e posturas de vida, diante da diversidade que é cuidadosamente programada para the ser ofertada, criando a ilusão que sua escolha é total. Hedonismo e consumo formam par perfeito para a lógica do mercado onde se amplia a ideia do objeto consumido, que pode ser tanto um acessório da moda como um serviço ofertado.

$\mathrm{Na}$ mesma direção de se refletir sob que esquemas sociais se dá o funcionamento do ser humano atual, Lipovetsky é autor de contribuições importantes sobre a sociedade pósmoderna, afirmando que esta se encontra no que denomina a segunda revolução individualista, caracterizada pelo processo que nomeia de personalização. A diretriz contemporânea configurada em nova forma de organização e controle social que emerge de rupturas com a ordem disciplinar-revolucionária-convencional predominante até meados do século XX, promove a descontinuidade com as sociedades modernas caracterizadas por funcionamento democrático-disciplinar, universalista-rigorista e ideológicas-coercivas (Lipovetsky, 1989). Agora, o valor maior é o desenvolvimento da personalidade íntima de cada indivíduo onde as necessidades subjetivas são essenciais e concomitantemente as instituições são moduladas de acordo com esse fato. Como consequência de caráter 
negativo o autor aponta o rompimento com processos sociais disciplinares, mas por outro lado faz-se uma sociedade que considera mais os aspectos humanos, a naturalidade, cordialidade e humor. O sujeito contemporâneo busca uma vida livre de coerções e entende que a sua escolha de como ser no mundo não deve ter restrições.

Para o autor acima, esse processo emergiu na modernidade, não tratando, portanto a passagem de uma fase à outra, com descontinuidade. Nos tempos modernos inicia-se um movimento de recuo de processos disciplinares que passam a conviver já com aspectos hedonistas e personalizados, ou seja, a era de revoluções, de escândalos e de esperanças no futuro terminou. Vive-se com indiferença para com a grande tribo da humanidade, em que é óbvia a importância da autonomia das pessoas que se sentem saciadas e estagnadas. Ao ritmo desenfreado de mudanças em vários campos da vida humana iniciado na modernidade, a geração pós-moderna reage com apatia. Não há planos para o futuro, não há intenções de mudança, não há pelo que lutar, a não ser o viver aqui-agora, o que é paradoxal se for lembrado que se vive num momento global em que cada vez mais dever-se-ia prever e organizar o futuro (Lipovetsky, 1989).

A indiferença contemporânea se transveste em metáfora do vazio do existir denominado por Lipovetsky (1989) de vazio da pós-modernidade . A partir do vazio e do estado narcisista - referindo-se o autor à passagem para o individualismo total - não se abandona o consumo deflagrado na modernidade, só muda a sua qualificação, pois o ato de consumir amplia suas fronteiras, onde tudo se absorve em consonância com o estado de vazio. Mas para isso o sujeito atual redistribui seus investimentos psíquicos relativos à esfera pública, direcionando-os agora, para a esfera privada, o que se apresenta como certo descompromisso político com o coletivo e alto investimento nas questões subjetivas. Sendo assim, cada indivíduo segue suas próprias demandas, deslizando pela vida, aportando provisoriamente onde lhe convém a cada momento e logo partindo. Como metaforicamente o autor demonstra que a imagem desportiva do homem pós-moderno que melhor ilustra esse seu movimento seria a asa delta, o windsurfe e o skate - o homem desliza pela realidade, sem aprofundamentos e com indiferença descontraída.

A autoridade é o próprio sujeito narcísico ou seja, ele comanda o mercado que deve seduzi-lo a preencher o vazio. Isto é, o sujeito é comandado pela sua subjetividade, processo este que é acompanhado pelo descrédito de instituições que tradicionalmente dirigiam a sociedade: do saber, poder, trabalho, exército, família, Igreja, partidos, etc. Não são estas instituições que definem as escolhas e sim, a psicologização da sociedade, tornando possível que várias ofertas, várias opções coexistam de forma indiferente como cita o autor "a indiferença pura designa a apoteose do temporário e do sincretismo individualista" (Lipovetsy, 1989, p. 39), processo este que permite várias combinações da forma de existir. Nesse grande espectro de possibilidades de ser no mundo e consequentemente de diversidade de consumos, o capitalismo encontra um terreno fértil para a experimentação, sem grande resistências do mercado narcísico sedento de preenchimentos de vazios quase tão diversificados quanto às pessoas.

Ao demonstrar a importância para o sistema que tanto necessita dessa indiferença para seu funcionamento, o autor lança a questão do paradoxo do mesmo sistema concomitantemente enviar mensagens sob diversas roupagens para promover a participação, a educação e o interesse dos indivíduos. Mas a intenção é subliminar e está na forma que se dá, pois são as mesmas organizações que produzem a apatia de massa. Em outras palavras a indiferença é produto da saturação, da informação e do isolamento e não se refere à falta de motivação, mas aos juízos flutuantes, onde não há apego absoluto, não existem certezas absolutas e as opiniões podem sofrer muitas e rápidas modificações. 
Como consequência dessa condição volátil, modifica-se também a relação com o tempo do sujeito pós-moderno, onde se esvaem o sentimento de pertença a um processo histórico e a percepção de que a sociedade atual é resultado de gerações passadas e deveria ser responsável pelas condições das gerações futuras. O viver aqui-agora retrata a despreocupação com tradições e instituições historicamente relevantes, da mesma forma que se evita o desespero de futuro duvidoso, condições férteis para que o mercado exacerbe a oferta de produtos que aperfeiçoem o bem estar presente seja do ponto de vista material, de saúde e psicológico.

Um aspecto bastante importante refere-se à afirmação do autor de que na contemporaneidade observa-se a psicologização do social, isto é, o coletivo é entendido e vivido com as lentes da subjetividade sendo que esse processo se estende para todas as esferas da vida humana, onde se pode incluir a relação do indivíduo com as instituições normatizadoras da sociedade. Daí a importância da análise transdisciplinar dessa situação especial que envolve as instituições judiciárias, quando se que investiga motivos para a não efetividade do sistema de justiça. Pois, para Lipovetsky (1989, p.53) "o adestramento social já não se efetua através da coerção disciplinar nem mesmo da sublimação; efectua-se por meio da auto-sedução. O narcisismo... socializa dessocializando, põe os indivíduos de acordo com um social pulverizado, glorificando o reino da plena realização do Ego puro".

Entende-se a partir desse pressuposto que ao se relacionar com pessoas, grupos, instituições de todos os tipos, o sujeito pós-moderno usa esse padrão relacional, onde ele mesmo é a direção e a finalidade. Portanto, a ética do sujeito narcísico acompanha o modelo do Eu atual sendo hedonista, permissiva , não conduzindo o indivíduo para grandes esforços que não sejam relativos ao seu desejo. Dessa forma, não há mais uma motivação para atitudes de sacrifício relativas a grandes fins sociais.

Do ponto de vista da convivência social, há uma armadilha muito importante nesse processo de subjetivação. Pois, na medida em que os indivíduos se libertam das amarras sociais e das normas de costumes em busca de viver de acordo com seu verdadeiro Eu, mais suas relações se complicam e os tornam muitas vezes associais. A relação íntima ou não entre as pessoas, exige limites e barreiras, sob o risco de se tornar um palco de expressões de impulsos positivos e negativos, portanto as regras impessoais promovem a proteção dos próprios indivíduos. No caso de uma nova forma de ser no mundo onde o referencial principal é o si-mesmo, as relações podem se tornar fratricidas. A reação dos próprios sujeitos nesses aspectos é por um lado se excluir cada vez mais de relações anônimas com desconhecidos com certa intenção de se proteger, mas por outro lado se aconchegam a grupos restritos onde compartilham algumas singularidades da busca de sua real intimidade (Lipovetsky, 1989). É essa tendência de subjetivação da pós-modernidade que o autor denomina de psicologização isto é, tudo deve passar a ser dito pela primeira pessoa, a autenticidade e a sinceridade se tornam imperativos e a norma é expressar as emoções genuínas, a forma particular de pensar, as motivações mais essenciais de sua vida.

Não é difícil concluir que essa configuração entre o foco no si-mesmo com o consequente afastamento dos códigos sociais, seria terreno propício a uma barbárie coletiva e a expressões frequentes de violência. Tem-se, portanto, uma forma nova e típica de adesão à convivência social, onde o narcisismo contemporâneo renuncia a grande ortodoxias, desarma o moralismo, a intolerância, as contradições e excomunhões e, ao mesmo tempo realiza adesões que são fundamentadas em ditames momentâneos e lábeis, mas com indiferença e sem grande motivação. Mas principalmente as relações sociais ocorrem de maneira a atender o que no fundo, o sujeito intenta, e assim se configuram em todas as relações o uso de estratégias que permitam o indivíduo alcançar o que deseja. Não é difícil encontrar esse padrão, por exemplo na vida profissional onde se busca a ascensão não 
somente para obter maior benefício financeiro, mas para provocar inveja no outro - o que é consequência de funcionamento narcísico - gerando uma selva onde todos competem e manipulam todos para que seus fins, isto é, que sua personalização seja atingida.

Esse modelo se repete nas relações privadas, que inclusive não têm mais o caráter de refúgio afetivo, sendo comum encontrar nos diversos meios informacionais, orientações enlatadas de como se posicionar em eventos sociais, como ser pais, como ser homem e mulher numa relação íntima, enfim... como ser nesse mundo atual para ser você mesmo e atingir sua metas subjetivas. Que tarefa hercúlea!

A convivência humana se torna na pós-modernidade, nos relacionamentos públicos ou privados, um espaço de relações de dominação e inferiorização, de sedução fria e intimidação. O que não deixa de ser uma forma violenta de se relacionar e, sendo assim, não é exatamente que a violência tenha diminuído, pois para Lipovetsky (1989) se convive com ameaças e realidades de muita violência, mas a ampliação da forma intrusiva e indiferente pelo outro, que se estende para todas as relações sociais, é que torna as relações humanas conflituosas pois há a violência implícita.

Para o autor acima, o culto ao consumo, as mudanças nas configurações familiares, os modelos educacionais permissivos, a importância da imagem, são alguns dos fatores que geram personalidades narcísicas que se traduzem em atores de relações cada vez mais bárbaras e combativas. A sociabilidade e a cooperação, a busca de uma vida leve e com qualidade - hedonista - são manifestações aparentes que escondem com cinismo, a simulação e a exploração do semelhante em busca dos interesses pessoais e sem considerar a consequência para o futuro da sociedade. Na verdade, parece que há novas normas sociais que atendem a também um novo momento histórico da sociedade (Lipovetsky, 1989).

Esse momento pode ser explicitado pelo fato de que a vida humana na atualidade se caracteriza pelas contradições, pois ao mesmo tempo em que as cidades se desenvolvem e a oferta de possibilidades de encontro entre as pessoas se amplia, mais os sujeitos sentem-se sós. Apesar de terem se libertado de uma série de amarras sociais antigas relativas às relações afetivas, menos os indivíduos conhecem relações profundas e intensas. O que se encontra é o sentimento de solidão, a dificuldade de sentir e de sair de si e ir ao encontro do outro. Talvez essa experiência do nada, do vazio, do nem uma coisa nem outra ou, as duas coisas ao mesmo tempo, conduza o indivíduo a buscas contínuas e breves de novas relações.

Essa configuração paradoxal de vida encontra eco na proposta de complexidade de Edgar Morin (1996b) apresentada anteriormente, onde uma das constatações é que a vivência atual de paradoxos exige uma lente específica para o estudo e intervenção sobre a realidade, onde não há mais efetividade de visão linear e determinista. Inclusive a ideia de sujeito que apresenta paradoxos e contradições, como se pode observar nos estudiosos da subjetividade contemporânea só pode ser entendida para Morin (1996b) sob uma perspectiva do pensamento complexo que inclui ambivalências e o aspecto organizacional de indivíduo como resultante de vários determinantes na sua estruturação e funcionamento.

De certa forma, pode-se dizer que o indivíduo pós-moderno é informado e consequentemente responsabilizado pelas suas escolhas. $\mathrm{O}$ bombardeamento de informações para com um sujeito narcísico e que se afastou de controles tradicionais de comportamento, tem provocado a fragmentação da personalidade, onde a lei é a possibilidade de coexistência de contrários: ao mesmo tempo em que pode ter acesso a cuidados de saúde, o indivíduo se arrisca em esportes e atividades de risco ou, abandonou regras e a postura de esforço e, no entanto procura dietas que exigem muita disciplina e método para levar ao bem-estar. 
Verdades absolutas não são bem recebidas na pós-modernidade pois sempre poderá existir a outra possibilidade, sendo assim na era atual o aspecto individual predomina sobre o universal, o psicológico sobre o ideológico, a comunicação sobre a politização, a diversidade sobre a homogeneidade, a permissividade sobre a coerção. É possível observarse também o impacto dessa lógica inclusive nos ideais de justiça pois "mesmo se as reivindicações dos grupos continuam a ser formuladas em termos de ideal de justiça, de igualdade e de reconhecimento social, e sobretudo em razão do desejo de viver mais livremente que descobrem uma autêntica audiência de massa (Lipovetsky, 1989, p. 108)".

Observa-se certa tolerância com as desigualdades sociais, legitima-se elites de poder e de saber, mas não se aceita o controle do desejo e da forma como se escolhe viver a vida. A impulsividade modernista necessária aos movimentos subversivos da época se rende ao modo de vida eclético segundo parâmetros subjetivos. Em outras palavras, o grande ideal a ser perseguido é o direito à autonomia individual. No entanto esta liberdade tem limites, gerados pelo sistema capitalista que exige o trabalho, o que tem direção oposta ao hedonismo, à recusa de esforço e de disciplinamento. Origina-se então uma situação paradoxal onde os indivíduos consomem cada vez mais na busca do bem-estar o que exige maior produção, sendo que essa mesma sociedade não consegue atender tamanha demanda, que exige por sua vez, muito trabalho! Para fugir da provável armadilha da solidificação de um Estado pretensamente nutridor de necessidades - não esquecendo que estas são impossíveis de serem totalmente satisfeitas para um Eu narcísico - poderia o Estado acompanhar a flexibilização da sociedade, diminuindo a sua distância com relação à população, tornando organizações mais maleáveis, disseminando e ampliando responsabilidades sociais, enfim, buscar formas de adaptação do Estado à sociedade pósmoderna (Lipovetsky, 1989).

O pós-modernismo se caracteriza por movimento hipertrófico de cultura sedimentada na negação de toda ordem estável isto é, o pós-modernismo não tem para esse autor, caráter descontínuo com a modernidade, pois o embrião de duas de suas principais características, já podem ser encontrados nessa fase anterior: a tendência à personalização e a redução progressiva do processo disciplinar.

Longe de ter apresentado todas as características implicadas na existência do sujeito pós-moderno, elencou-se aquelas que se considerou relevantes para se compreender algumas especificidades dessa configuração psicossociológica na relação que se estabelece entre os indivíduos e o sistema de justiça.

\section{A subjetividade pós- moderna e a efetividade do sistema de justiça}

Conforme foi possível observar nos itens anteriores a subjetividade do sujeito contemporâneo apresenta características marcantes e que sob a visão da complexidade estão em constante mutação, atingindo várias áreas da existência humana. A dimensão dessa temática é bastante significativa. Como exemplo tem-se que com a revolução tecnológica relativa a própria engenharia genética, já se cogita a questão de como será o futuro ser humano daqui algumas décadas, considerando o impacto da tecnologia de informação sobre a subjetividade do que talvez se venha a denominar futuramente homem-máquina (Regis, 2012) e, consequentemente de todos os campos do conhecimento que a ele se referem, como no caso do Direito. Faz-se necessário relacionar, portanto o momento histórico do homem que é objeto do campo jurídico para se compreender de que maneira este sujeito jurídico pós-moderno se apresenta.

Essa dinâmica sociológica até aqui apresentada é campo aberto para criar inúmeras demandas judiciais pelo comportamento consumista em si e pelos desdobramentos sociais 
em termos de desigualdades e violação de direitos. O homem é fadado, portanto a consumir e estar bem! E o sistema de justiça parece ter se transformado numa via possível de se buscar o ideal de bem estar fundamentado tanto na perspectiva subjetiva que cada indivíduo possui sobre o que seria justo para ele, como no sentido de que suas demandas judiciais não são descoladas de um contexto sócio histórico, que se caracteriza como anteriormente afirmado pela fluidez, negação da autoridade, e incentivo direto e constante a todo tipo de consumo.

Como afirma Sanches (2009), no momento recente da evolução do Direito, que se afasta gradativamente de paradigmas mais lineares, abre-se espaço para o estabelecimento de relações com outros campos de conhecimento. A Sociologia, a Antropologia e a Psicologia se apresentam como fontes de contribuições relevantes para o entendimento de dificuldades encontradas pelo exercício do Direito. Surge então a necessidade de se analisar o comportamento atual do usuário do sistema de justiça à luz das características da contemporaneidade, com destaque para a ideia de justiça fundamentada nos parâmetros dessa configuração sociológica.

O comportamento consumidor generaliza-se para o sistema de justiça onde o jurisdicionado tem a expectativa de que esse sistema resolva rapidamente e sem maiores aprofundamentos aquilo que o sujeito quer e principalmente da forma que deseja. $\mathrm{O}$ indivíduo possui, portanto um entendimento específico do que seria fazer justiça e assim não se busca muitas vezes a lei real e sim a que se deseja.

Reafirmam-se, portanto as contribuições de estudos sobre a subjetividade contemporânea (Baumann, 2001; Dufour, 2008; Lebrun, 2004; Lipovetsky, 1989) demonstrando a presença de um sujeito pós-moderno que estabelece relações fluídas onde não há espaço para o desprazer, para a espera, dentre outros atributos das relações humanas. Esse fato tem, segundo Brito (2012) em seu ensaio teórico "O sujeito pós-moderno e suas demandas judiciais", forte influência sobre a busca incessante de algum meio que satisfaça as necessidades pessoais, onde se incluem as demandas ao sistema de justiça. Nessa perspectiva, a insatisfação, a superficialidade de conhecimentos sobre os direitos, a premência pelo prazer constante e a ausência de referências pode contribuir como terreno fértil para a ilusão de que se criando novas leis ou aprimorando o sistema de justiça, se atenderia, finalmente, o cidadão.

A consideração de que o campo jurídico é permeado por esta construção social da subjetividade humana faz com que o Direito se humanize, traga para perto de si aquele que é razão da sua existência: o homem. A abertura para a dimensão subjetiva dos fenômenos sociais, tal qual é a relação do homem com as leis, implica num movimento dialético que supera a dicotomia entre indivíduo e sociedade, e onde a subjetividade passa a ser elemento constituinte das relações sociais (Gonçalves, 2010). Dessa forma a Psicologia, como ciência que tem como objeto a subjetividade, passa a ser elemento fundamental na pesquisa e intervenção sobre as relações que se estabelecem entre o indivíduo e o sistema de justiça.

Se a normatização social é papel do Direito, uma das primeiras tarefas é o conhecimento sobre essa sociedade a ser foco de legislações para que estas tenham sucesso em sua aplicabilidade. Caso isso não ocorra - e realmente muitas vezes é esta a situação - o Legislativo elabora leis distantes de uma realidade concreta e o Judiciário, não poderia ter outro resultado senão o fracasso da aplicação da lei e de seu intento de fazer justiça. Trindade (2011) expõe claramente o momento em que o saber e a prática jurídica se encontram, ao afirmar que o mundo atual, complexo e globalizado, superou o 
disciplinamento do saber que acabam reduzindo o ser humano, a vida e o mundo, o que deve ser urgentemente reformado em função da sobrevivência da própria ciência. Para o autor à teoria do Direito, em busca da superação da crise atual do pensamento jurídico atual, urge a percepção da necessidade de sua integração aos conhecimentos sociais. Dessa forma a ciência jurídica deve ultrapassar a ideia limitada de sua autonomia e independência e que "o jurista é um técnico da subsunção do fato concreto esterilizado à assepsia da norma abstrata (Trindade, 2011, p. 28)".

Sobre essa necessidade de se aproximar mais do jurisdicionado, Sanches (2009) também constata que todas as mudanças históricas das ideias e práticas jurídicas chegam na pós-modernidade com a tarefa de fundamentar-se em novos paradigmas que abram portas para a transdisciplinaridade, onde a Psicologia em parceria com o Direito ocupa papel fundamental " na solução para a estagnação das fontes jurídicas, de modo a viabilizar a efetivação da verdade real e a maior consideração do ser humano e dos fatores que o envolvem" (Sanches,2009, p.29). A falta dessa frutífera e inevitável composição de saberes é uma das importantes variáveis contribuintes para a disfuncionalidade do sistema de justiça o que é claramente observado nas demandas jurídicas na área criminal, trabalhista, familiar, de direitos da criança e adolescente, entre outras. De maneira mais específica tem-se o exemplo da lei 11.340/2006 - Lei Maria da Penha, que apesar de ser legislação de amplo conhecimento pela sociedade brasileira, ainda encontra muitas dificuldades em sua aplicação. Pois, segundo Carvalho (2015), é complexo o fato jurídico - violência doméstica contra a mulher - que diz respeito a essa lei, envolvendo aspectos psicológicos, socioculturais, familiares e econômicos. A tessitura do problema implica também, que haja um entendimento muito particular do que seria a efetividade da aplicação da lei 11.340/2006 o qual, fundamentado na concepção subjetiva de justiça para os indivíduos envolvidos, pode ser aspecto relevante para a explicação do alto índice de desistências das mulheres que acionam o sistema jurídico e depois dele desistem (Carvalho, 2015).

Se a necessidade é também de que o Direito considere não somente a subjetividade dos sujeitos, mas que a entenda a partir de um contexto que a constrói, fazem-se pertinentes as reflexões de Dufour (2008) ao descrever como um dos mandamentos do divino mercado, a forma que os indivíduos se relacionam com a lei na contemporaneidade liberal. $\mathrm{O}$ autor chama a atenção inicialmente o quanto há integração perfeita entre o liberalismo a as atividades criminosas, pelo funcionamento intrínseco do primeiro, pois nesse sistema a honestidade não é claramente necessária, uma vez que a verificação do livre acesso à concorrência assim como o caráter legal da prova só ocorre a posteriori. Como o liberalismo transforma tudo em mercadoria inclusive a justiça - não é difícil concluir que a corrupção é inerente ao sistema liberal e a relação de crescimento entre a corrupção e o liberalismo será diretamente proporcional. Tal fato seria uma das consequências de que noção de lei está mudando, pois se antes se aplicava a lei, agora se faz justiça. A diferença desses fatos para Dufour (2008) é que o princípio modificou, pois a aplicação da lei prevê a existência de um terceiro imparcial e neutro acima de interesses privados e fazer justiça seria consequência da resolução de conflitos de interesse entre dois lados.

Ainda para esse autor, a solução exclusiva que se apresenta para os conflitos decorrentes da "concorrência desenfreada dos egos causadas pelo liberalismo é penal: "é ter os mesmos direitos que aqueles de quem nos proclamamos diferentes" (Dufour, 2008, p. 228). Como consequência surge "a inveja de penal" (Dufour, 2008, p.228) que predomina entre os sujeitos pós-modernos e que abarrotam escritórios de advocacia de pedidos de 
reparação de todos os tipos . Essa tendência de processar sem limites facilitada pelo direito privado americano se associa ao fenômeno da vitimização e acaba fazendo do Direito e, em especial para os advogados especializados nessas demandas, um grande negócio e "é por isso, que a justiça, por funcionar cada vez mais conforme as lei do comércio, não está ela mesma ao abrigo das errâncias legais que caracterizam o empreendimento" ( Dufour, 2008, p. 229). A ideia quase transcendental e tradicional de lei está sendo substituída cada vez mais pela justiça num sentido mercadológico e consequentemente pelo decreto, procedimentos e negociações que existirão em proporção cada vez maior na medida em que não houver lei. Não se entende aqui que um número maior de leis seria o caminho, mas sim que a falta de efetividade da lei impede que haja a racionalização e democratização do Judiciário. Tal fato poderia evitar o abandono daquilo que seria originalmente o foco do Direito - a busca da verdade - em troca de negociações entre o acusado e o juiz, o que é muito bem ilustrado no Direito francês em casos que a investigação pode ser suspensa e haver negociação da pena em função de confissões do acusado.

Também em Bauman (1998) pode ser encontrada reflexão sobre a questão da justiça na pós-modernidade ao afirmar que esta necessita que o Estado seja estabelecido e com isso perde-se a singularidade do indivíduo que passa a ser entendido como cidadão. Esse processo é necessário para o funcionamento do sistema de justiça, mas não à custa da redução, do empobrecimento e da diluição do que é a amplitude do ser humano, captada segundo o autor, pela ética. Num certo sentido, a justiça se afastaria então de suas origens na ética, o que não deve ocorrer para manter seu significado de justiça, principalmente não se abandonando aos poderes e razões deterministas do Estado, assim como não se rendendo às tentações totalitárias.

Se a pós-modernidade se caracteriza por paradoxos como se afirmou anteriormente, é essa a situação paradoxal que envolve o Estado liberal e a lei: se proíbe e se propicia a mesma coisa - como a lei então iria ser aplicada? O interesse privado suplantou a ideia transcendental de lei onde se visava sempre a verdade e igualdade, que por mais que fossem inatingíveis, eram a bússola do sistema de justiça.

Apesar da escolha da perspectiva sistêmica para se analisar o tema do estudo, sabe-se da dificuldade de se realizar essa articulação, pois o campo jurídico por excelência necessita dos fatos objetivos para serem analisados também por legislações objetivas que serão aplicadas de maneira linear. O juiz, conforme afirma Vasconcellos (2003) procura afastar as possíveis influências da subjetividade na análise das causas levando-o a focalizar essencialmente o que consta nos autos, na busca da verdade. O pressuposto é que existe a melhor justiça a ser feita a qual está expressa na lei, sendo o magistrado um instrumento da expressão justa. O pensamento complexo e a abordagem sistêmica trariam novas questões nessa atitude, como por exemplo, a impossibilidade de negação plena da participação da subjetividade do juiz em sua análise, ou o fato de que talvez os aspectos mais relevantes da situação jurídica, não estejam nos autos, e por aí vai...

A importância da comunicação no sentido sistêmico para a prática jurídica, é reconhecida por Fiorelli et al (2008) ao afirmarem que a adoção da abordagem sistêmica pelo profissional de Direito permitirá identificar as várias modalidades de comunicação e o conteúdo que se comunica nos processos, o que interfere na percepção que cada integrante tem sobre as mensagens trocadas na prática jurídica. Inevitavelmente esse fato ocasionará mudança no próprio papel do Judiciário na figura do juiz, pois, ao se apropriar e decodificar os conteúdos presentes no andamento dos processos, e tendo adotado o paradigma da 
complexidade, o magistrado poderá reconhecer que não raro os jurisdicionados lhe impõem e dele esperam papéis maternos e paternos, como se afirma ao analisar o papel do juiz na pós-modernidade, "não só o pai que impõe limites, mas a mãe que acolhe, ouve e intui" (Bortoleto \& Carvalho, 2012, p. 35).

A tendência de se analisar linearmente as demandas jurídicas tem suas origens na história do campo jurídico e se amplia inclusive para os outros campos de conhecimento que complementam o saber jurídico. A resistência à mudança de lugar e de olhar pode ser evidenciada inclusive nos próprios profissionais de Psicologia, que em sua formação já têm a inclusão da subjetividade e da influência do meio social sobre a mesma. Pois, esses profissionais, ao adentrarem no sistema de justiça, se não estiverem atentos, nos estudos psicossociais por eles realizados estarão funcionando de maneira julgadora e prédeterminista, o que os fazem perder a riqueza de colaborar com a produção de um novo significado junto ao processo em questão e junto às partes envolvidas, permitindo a subjetivação do objetivo, pois o reducionismo e a linearidade não contemplam todas as possibilidades de análise (Brito, 2005).

Apesar das grandes dificuldades diante da busca de efetividade do sistema de justiça, alguns movimentos têm sido realizados no Brasil. O Conselho Nacional de Justiça encampou um projeto de pesquisa denominado: "Causas do progressivo aumento da demanda judicial cível repetitiva no Brasil e propostas para a sua solução" (Barbosa, 2010) cujo relatório final indica que a resolução de conflitos deve contar com a inserção e estímulo de outras alternativas para seu enfrentamento que não a forma adjudicada além de apresentar propostas contribuintes para que se diminuam as demandas repetitivas ao Poder Judiciário. Isto é, vislumbra-se a ideia que há presença de variáveis nas demandas judiciais que não são contempladas pelas estratégias e instrumental tradicional do Direito.

Sendo a Psicologia, por excelência o campo de conhecimento que estuda a subjetividade do homem, terá importantes contribuições para o Direito na compreensão de seu jurisdicionado e da relação que estabelecem entre si - indivíduo e sistema de justiça. No entanto apesar dessa aproximação ser fundamental, enfrenta dificuldades para sua superação, pois segundo Huss (2011) existem várias diferenças epistemológicas entre o Direito e a Psicologia.

Apesar dos motivos para afastamentos entre o campo jurídico e outras ciências humanas e sociais, entende-se que o diálogo é possível respeitando as singularidades e, mais ainda usufruindo-se deste diálogo, pois não raras vezes, são as composições de práticas e fundamentos teóricos que apontam caminhos. Como afirmam Minuchim et al (2011), a complexidade da sociedade do século XXI, ocasiona vulnerabilidades em todos as esferas sociais e a desintegração dos serviços - de saúde, assistência social, jurídicos principalmente prestados a indivíduos em situação de maior vulnerabilidade social, e muitas vezes propiciam a manutenção e complicação de conflitos, o que leva a circularidade da situação sem resolução.

Para Carvalho (2014; 2015) essa talvez seja uma das variáveis promotoras do que se denomina judicialização de conflitos sociais. Pois, questões de ordem psicológica e/ou social não são abordadas efetivamente por políticas públicas adequadas e acabam se transformando em demandas judiciais. Cabe, portanto ampliar estudos que considerem a influência de aspectos psicossociais na efetividade do sistema de justiça. Pois a busca de justiça não pode ser descolada da subjetividade dos seus autores e atores, a qual, em última instância é retrato de processos sociais que determinam suas manifestações e intentos. 


\section{Considerações finais}

$\mathrm{O}$ que se procurou aqui apresentar foram os principais pressupostos acerca de que tipo de olhar científico se mostra mais pertinente à realidade atual do sistema de justiça, ao mesmo tempo que se caracterizou, sob a perspectiva de autores de diversos campos do conhecimento , a subjetividade do indivíduo contemporâneo. Essa proposta teve a intenção de relacionar essa forma de ser no mundo típica da pós-modernidade com suas demandas ao sistema de justiça, o qual também é elemento integrante do sistema mais amplo.

Sendo assim, se o Poder Judiciário se debate com a realidade da não efetividade de suas ações, a linha do pensamento aqui proposta é que talvez existam descompassos entre o que o Judiciário pós-moderno define como efetividade e qual é a motivação e intenção dos sujeitos pós-modernos que o procuram, as quais são resultantes de um funcionamento social específico, processual e histórico.

O convite desse estudo é ampliar o espectro da reflexão sobre a promoção de justiça mediante a colaboração das diversas disciplinas implicadas no problema. A postura transdisciplinar envolverá necessariamente projetos de pesquisa fundamentados na complexidade das situações jurídicas e que poderão assim subsidiar práticas mais efetivas pelos sistemas de garantia de direitos e efetividade da justiça.

Procurou-se demonstrar que a subjetividade de todos os atores envolvidos com as demandas jurídicas - sejam os profissionais ou os jurisdicionados - está presente e sua influência é significativa desde a composição da demanda até a aplicação e execução da lei. Dessa forma, a Psicologia tem como um de seus papéis na lide jurídica e em qualquer discussão sobre a relação dos cidadãos com o sistema jurídico, proporcionar a leitura sobre como a subjetividade está se configurando em cada momento histórico da sociedade e demonstrar as implicações de tal fato que muitas vezes determinam o lugar e a função de pessoas e instituições protagonistas das problemáticas jurídicas. Tal fato não minimiza de maneira alguma a importância do lugar tradicional da Psicologia no campo jurídico iniciado desde o século XIX, com a intervenção mediante avaliações psicológicas de situações nas causas criminais, e que foram se estendendo para causas familiares, trabalhistas, de direitos da infância. Portanto, a própria Psicologia (e os psicólogos!) devem observar seu papel de tradutor e intérprete da situação do sistema de justiça considerando as singularidades a que sua prática está sujeita em função de uma configuração psicossocial específica.

Com isso, a intenção final é deixar demarcado que a concepção de justiça advinda da configuração sociológica pós-moderna, pode ser um limite para os resultados efetivos do Judiciário perante o cidadão, mas também pode ser uma oportunidade. Se houver abertura para reflexões internas dos três poderes e movimentos políticos para se rever as estratégias de se fazer justiça e para que se efetive um Direito pós-moderno no país, estar-se-á colaborando para o desenvolvimento da sociedade. Dessa forma talvez um dia seja quase desnecessário um sistema de justiça com excessivas demandas de atuação, pois talvez houvesse menos leis... Mas que tivessem em sua essência a garantia de direitos para todos. 


\section{Referências}

Barbosa, C. M. (Coord.) (2010) Projeto causas do progressivo aumento de demandas judiciais cíveis repetitivas no Brasil e propostas para solução. Relatório final. Conselho Nacional de Justiça e Pontifícia Universidade Católica do Paraná. Curitiba.

Bauman, Z. 0 mal estar da pós-modernidade. 1ّ. Ed.Rio de janeiro: Jorge Zahar Editor. . (1999) Globalização - as consequências humanas. Rio de Janeiro: Zahar. . (2001). Modernidade líquida. Rio de Janeiro: Jorge Zahar Editor..

. (2008). Vida para consumo - a transformação das pessoas em mercadorias.. Rio de Janeiro: Zahar.

Bortoleto, L; Carvalho, M. C. N. ( 2012) Sistemas de Justiça e Direitos Humanos relações interdisciplinares. In: Maria Cristina Neiva de Carvalho(Org.). Sistemas de justiça e direitos humanos: relações interdisciplinares. Curitiba: Juruá

Brito, L. M. T (2005). Reflexões em torno da psicologia jurídica. In: Roberto Cruz; Saidy Karolin Maciel ; Dario Cunha Ramirez, ( orgs). 0 trabalho do psicólogo no campo jurídico. São Paulo: Casa do Psicólogo.

. (2012). O sujeito pós-moderno e suas demandas judiciais. Revista Psicologia: Ciência e Profissão, vol 32, no. 3. Brasília.

Carvalho, M. C. N.(2014) 0 judiciário e as políticas públicas: que relação é essa? In: Barbosa, C. M.; Pamplona, D. A. (Coords.). Políticas públicas, democracia e poder judiciário [livro eletrônico]. Curitiba: Letra da Lei. Disponível em: <http://www.direitosocioambiental.com.br/publicacoes-2/politicas-publicasdemocracia-e-poder-judiciario/>. Acesso em: 28 fev. 2015.

(2015). A efetividade do sistema de justiça sob a lente do descompasso entre a prestação jurisdicional e a demanda do jurisdicionado: um estudo a partir da Lei Maria da Penha. Tese de Doutorado Não Publicada, Programa de Pós- Graduação em Direito, Pontifícia Universidade Católica do Paraná. , Curitiba. 
Casanova, P. G. (2006) As novas ciências e as humanidades: da academia à política. São Paulo: Boitempo Editorial.

Dufour, D.R..(2008) 0 divino mercado - a revolução cultural liberal. 1ํㅡㄹ. Edio de Janeiro: Companhia de Freud.

Fiorelli, J. O.; Fiorelli, M. R.; MALHADAS, M. J. J (2008). Psicologia aplicada ao direito. São Paulo: LTR..

Gonçalves, M. G. M. (2010) Psicologia, Subjetividade e Políticas Públicas. São Paulo: Cortez.

Huss, M. T.(2011). Psicologia forense - pesquisa, prática clínica e aplicações. Porto Alegre: Artmed.

Lebrun, J.P.(2004). Um mundo sem limite - ensaio para uma clínica psicanalítica do social. 1ํㅡㄹ. Edo de Janeiro: Companhia de Freud.

Lipovetsky, G.(1989). A era do vazio. Lisboa: Relógio D'Agua.

Minuchim, P.; Colapinto, J.; Minuchim, S. (2011). O desafio de trabalhar com famílias de alto risco social - uma abordagem sistêmica. São Paulo: Roca.

Morin, E. (1996a) A noção de sujeito. In: Schnitma, D.F. (org.) Novos paradigmas, cultura e subjetividade. Cap. 2: 45-55. Porto Alegre: Artes Médicas

Morin. E. (1996b)Epistemologia da Complexidade. In: SCHNITMAN, D F (org) Novos paradigmas, cultura e subjetividade. Porto Alegre: Artes Médicas.

Morin, E. (2000)Saberes globais e saberes locais: o olhar transdisciplinar. Rio de jnairo: Garamond,

Morin, E. (2013) A VIA - para o futuro da humanidade. 1a ed. Rio de Janeiro: Bertrand Brasil. 
Regis, F. (2012) Nós, ciborgs: tecnologias de informação e subjetividade homem-máquina. Curitiba: Champagnat

Sanches, A. L. N.(2009) Diálogos entre o direito e a psicologia. In: CARVALHO, M. C. N; Fontoura, T; Miranda, V. R. (orgs). Psicologia Jurídica - Temas de Aplicação II. p. 1730.1… ed. Curitiba: Juruá

Santos, B. S..(2005) El milênio huérfano - ensayos para uma nueva cultura politica. Rio de Janeiro: Graal.

Santos, B. S; Meneses, M. P. G. (orgs). (2009) Epistemologias do sul. Coimbra: Almedina.

Schor, J.B. (2009) Nascidos para comprar. 1a․ Ed. São Paulo: Editora Gente.

Sen, A.; Kliksberg, B. (2010) As pessoas em primeiro lugar - a ética do desenvolvimento e os problemas do mundo globalizado. São Paulo: Companhia das Letras.

Trindade, J. (2011) Manual de psicologia jurídica para operadores do direito. Porto Alegre: Livraria do Advogado.

Vasconcellos, M. J. E. (2003) Pensamento sistêmico - o novo paradigma da ciência. 2a edição. Campinas: Papirus.

Recebido / Received: 20/09/2015 Aprovado / Approved: 14/12/2015 